\title{
A Pandemia e seus (des)caminhos
}

Pandemic and its detours

Pandemia y sus (des) caminos

La pandémie et ses déviations

\section{Jorge França da Silva Medeiros}

\section{(2) OpenEdition \\ Journals}

\section{Edição electrónica}

URL: http://journals.openedition.org/espacoeconomia/13141

DOI: 10.4000/espacoeconomia.13141

ISSN: 2317-7837

\section{Editora}

Núcleo de Pesquisa Espaço \& Economia

\section{Refêrencia eletrónica}

Jorge França da Silva Medeiros, "A Pandemia e seus (des)caminhos », Espaço e Economia [Online], 18 | 2020, posto online no dia 22 abril 2020, consultado o 20 maio 2020. URL : http://

journals.openedition.org/espacoeconomia/13141; DOI : https://doi.org/10.4000/espacoeconomia. 13141

Este documento foi criado de forma automática no dia 20 maio 2020.

(C) NUPEE 


\title{
A Pandemia e seus (des)caminhos
}

\author{
Pandemic and its detours \\ Pandemia y sus (des) caminos \\ La pandémie et ses déviations
}

Jorge França da Silva Medeiros

1 Há muito tempo tentamos desvendar os inúmeros dilemas que cercam a vida no/do Planeta. As explicações, em sua grande maioria, têm partido de aspectos tautológicos da realidade e buscam revelar a interdependência de elementos constitutivos da vida social. Talvez a chave para se (re)interpretar esse novo momento seja a ideia de interdependência, tão cara à ciência moderna.

2 As últimas semanas têm nos mostrado o quanto os elementos da vida social passaram a ser redesenhados em diferentes escalas. Assim como em outros momentos da história, grandes transformações começam a bater à porta de milhões de pessoas espalhadas pelos mais diferentes continentes e regiões do planeta. E, para tentar explicá-las e compreendê-las, ainda que de forma aparente, precisamos lançar mão de duas outras noções: o tempo e o espaço.

3 A identificação da doença respiratória aguda causada pelo coronavírus (COVID- 19) ainda no dia 1 de dezembro de 2019, na província de Hubei, na República Popular da China inaugurou um novo momento das relações de interdependência entre pessoas, lugares, empresas e Estados Nacionais. Desde então e, sobretudo, após a OMS (Organização Mundial da Saúde) decretar no dia 11 de março de 2020 a situação de Pandemia, ou seja, quando o alastramento do vírus se tornou global, o tempo e o espaço não são mais os mesmos.

4 A explicação para tal constatação não parece simples. Tais noções nada mais são do que construções sociais modernas e, como tais, entram no movimento espiral de coletividades locais que juntas e articuladas às demais instituições sociais dão cara e forma ao mundo atual, de tal modo que podemos indagar: em que medida a situação de Pandemia passou a relativizar as noçóes de tempo e espaço e, simultaneamente, a (des)configurar o mundo atual? 
5 O desenvolvimento voraz das técnicas de produção nos colocou em níveis elevados de produtividade e nos fez acreditar na fábula da aldeia global, em que todos(as) compartilham dos mesmos gostos, sentidos, hábitos, ideias, etc. Esse mundo, da organização da vida e dos negócios mediante o aprimoramento das técnicas parece ter preparado a sociedade para o novo momento, em que tempo e espaço passam a se ressignificar.

6 Desde então, o tempo da produção, da realização do capital, em escala global tem sido colocado à prova. As economias liberais estimuladas pela ampla concorrência entre pessoas e empresas parece não encontrar saídas competitivas para suplantar os labirintos impostos pela nova condição sanitária do mundo.

7 A ilusão do desenvolvimento econômico estabelecido em programas, planos e discursos aparentemente progressistas, tende a conservar uma ordem social e política que se esgota em meio à proliferação do agente biológico e impõe uma rápida mudança de curso nas estratégias de produção da vida coletiva.

8 As bases materiais do mundo atual, nesse momento, passam a dialogar com outras instituições que, até então, estavam desalinhadas com o tempo da produção. A família e a igreja funcionam como o porto seguro de relações que passam a ser revistas e ampliadas, ainda que de maneira forçada.

9 Neste momento, de tamanha preocupação global, revigoram-se relações antes esquecidas pela aceleração do tempo da produção. Produzir, agora, significa, antes, refletir. A reflexão antecede a produção, justamente, porque esta foi impedida de continuar o ciclo de "prosperidade" amplamente divulgado pelas economias liberais. $\mathrm{O}$ espaço, antes pensado a partir de uma relação métrica e absoluta, se relativiza em meio às novas condições de realização da vida coletiva.

10 Evidentemente, a etapa primeira da reflexão não significa maior autonomia ou liberdade, mas sim, e, antes de tudo, necessidade. Trata-se da manutenção, em condições adequadas, do capital humano (da possibilidade de exploração do trabalho) para a reconstrução do sistema, cujas bases ainda passam por redefinição.

11 O impacto que a pandemia tem produzido no mundo ganha cada vez mais força quando pensado a partir das múltiplas cidades, sobretudo aquelas de concentram grandes aglomerações econômicas e populacionais. São nesses locais que a repetição da vida urbana cotidiana parece não ser mais estratégica. A letalidade associada à rápida capacidade de mutação coloca o agente biológico na condição de determinar o sentido de cidade em pleno século XXI.

12 A vida urbana se acostumou com o movimento, o ir e vir constante de pessoas e automóveis, trens, ônibus e metrôs colocou em cena as condições ideais para expansão do capitalismo. A circulação é inerente à cidade. 0 sentido espacial da vida urbana é medido pela extensão dos movimentos diários que os mais diferentes grupos de pessoas realizam. O simples deslocamento de uma posição A para uma posição B pode corresponder a perdas e ganhos monetários para dezenas de pessoas e empresas.

13 A rápida proliferação do vírus, o COVID-19, em praticamente todos os continentes impôs um redirecionamento da vida social. As cidades, antes pensadas como espaços estratégicos para a produção da riqueza material, viram-se ameaçadas. Os conteúdos urbanos (leia-se relações sociais) produzidos durante décadas passaram a negar as formas arquitetônicas (praças, shoppings, teatros, avenidas, fábricas, prédios 
corporativos, dentre outros.) pensadas para produzir e circular riquezas, sendo, gradativamente, sucumbidas pela nova forma de (con)viver na cidade.

Isso implica na maneira pela qual tempo e espaço passam a ser produzidos. Ao invés das grandes e movimentadas aglomerações surgem as "bolhas" digitais interdependentes que passam a produzir um novo conteúdo social e urbano, cujo fundamento é a conexão por segregação.

15 Tal condição requalifica e reconstrói a noção de espaço e tempo. A velocidade, o movimento e a instantaneidade com que a convivência na cidade é produzida, tende a ignorar a necessidade da aglomeração. Nesse contexto, o espaço pode ser vivido a partir da dimensão virtual. A onipresença é praticada por meio das telas touch screen, que redefinem a própria ideia de aglomeração.

16 A comunicação social, nesse caso, engendra um tempo. O tempo do encontro, da realização do contato presencial passa a se expressar pelo tempo do agora, em que todos compartilham das mesmas criações, emoções, sensações e reflexões por meio da explosão de lives, em aplicativos de interação social, sobre os mais diferenciados assuntos contemporâneos, incluindo temas sobre política, saúde, economia e até mesmo apresentações artísticas.

17 A reconstrução das noções de tempo e espaço permite um olhar diferenciado sobre como se costurou, ao longo dos anos, a relação entre a dimensão política, econômica e social. Os significativos avanços técnicos impõem uma nova forma de interação da vida coletiva e permitem sinalizar a construção de vias alternativas aos futuros projetos de reconstrução nacional em grande parte do mundo.

18 Em tempos pretéritos dificilmente chegaríamos a essa condição, dada a existência de ferramentas e equipamentos ainda incapazes de tamanha função. A novidade reside justamente na percepção desse novo conteúdo capaz de mobilizar uma quantidade expressiva de pessoas segregadas e conectadas em rede. Tal condição, por outro lado, impõe um redesenhar das formas de produzir, consumir, interagir e socializar bens e ideias. Se, durante muito tempo, a aglomeração funcionava como um pré-requisito para a exploração, agora parece anunciar o contrário.

19 Assim, a (des)configuração do mundo atual questiona o sentido de cidade, uma vez que o conhecido potencial de destruição do agente biológico ceifa a possibilidade de existência, única, da vida competitiva e individual, cujo tempo da produção se expressa por meio da aglomeração designando diferentes modelos de exploração.

20 A Pandemia causada pelo COVID-19 veio nos alertar e abrir nossos olhos e mentes para o surgimento de uma nova Geografia, cuja noção de fronteira não se restringe mais às negociações políticas e diplomáticas. E que a interdependência é uma necessidade urgente para mobilizar ações e reações compatíveis às novas necessidades médicas $\mathrm{e}$ sanitárias.

21 Aglomerar e explorar perde sentido. O confinamento de pessoas e a restrição da mobilidade significam a emergência de um novo tempo. O tempo da fábrica, do comércio e dos serviços passa a ser vivenciado em plataformas digitais que conectam os mais distantes pontos do território. A conexão pela segregação é o tempo presente, é a produção desmanchada por linhas e pontos interdependentes, revelando um olhar para si e para o outro e não mais para o sistema.

22 A mensagem da proteção e do abrigo como condição de manutenção da vida coletiva vem derrubando economias liberais que pouco, ou quase nada, tem de solidárias e vem 
permitindo a criação de uma nova consciência social que passa pela ressignificação da noção de tempo e espaço.

O tempo do relógio, da produção com hora marcada para chegar e sair do trabalho, da escola, do lazer, do acordar e adormecer cede, lentamente, o lugar ao tempo da criação, da reflexão e da percepção. São etapas imperativas que surgem no próprio movimento de reconstrução das coletividades locais atingidas pela Biologia que passam a produzir uma nova Geografia. Eis, aqui, um de seus (des)caminhos!

\section{RESUMOS}

A condição de existência da vida coletiva tem sido ameaçada pela proliferação do coronavírus (COVID-19) em praticamente todo o mundo. A situação de pandemia declarada pela OMS (Organização Mundial da Saúde) tem colocado em xeque as estratégias de desenvolvimento econômico liberais de inúmeros países, uma vez que a redução da mobilidade espacial, até então, a estratégia mais eficiente para o combate à pandemia, tem acarretado um forte processo de reconfiguração da vida social. A cidade, nesse contexto, tende a assumir uma nova condição de existência que passa pela requalificação das noções de tempo e espaço, bem como pela compreensão do movimento de reconstrução das coletividades locais. Nesse sentido, o presente texto busca refletir sobre esse novo momento que parece redesenhar um novo conteúdo geográfico, sobretudo nas cidades, por meio da conexão por segregação.

The condition of existence of collective life has been threatened by the proliferation of the coronavirus (COVID-19) in practically the whole world. The pandemic situation declared by the WHO (World Health Organization) has put in check the liberal economic development strategies of many countries, since the reduction of spatial mobility, until then, the most efficient strategy to fight the pandemic, has entailed a strong process of reconfiguration of social life. The city, in this context, tends to assume a new condition of existence that involves the requalification of the notions of time and space, as well as an understanding of the movement for the reconstruction of local communities. In this sense, this text seeks to reflect on this new moment that seems to redesign a new geographical content, especially in cities, through the connection by segregation.

La condición de existencia de vida colectiva ha sido amenazada por la proliferación del coronavirus (COVID-19) en prácticamente todo el mundo. La situación de pandemia declarada por la OMS (Organización Mundial de la Salud) ha puesto en jaque las estrategias liberales de desarrollo económico de muchos países, ya que la reducción de la movilidad espacial, hasta entonces, la estrategia más eficiente para combatir la pandemia, ha implicaba un fuerte proceso de reconfiguración de la vida social. La ciudad, en este contexto, tiende a asumir una nueva condición de existencia que implica la recalificación de las nociones de tiempo y espacio, así como la comprensión del movimiento para la reconstrucción de las comunidades locales. En este sentido, este texto busca reflexionar sobre este nuevo momento que parece rediseñar un nuevo contenido geográfico, especialmente en las ciudades, a través de la conexión por segregación.

La pandémie covid-19 menace pas seulement les conditions d'existence de la vie collective, mais aussi les stratégies libérales de développement de plusieurs pays. On se rend compte que la réduction de la mobilité spatiale est en train de provoquer une reconfiguration de la vie sociale. 
Dans ce contexte, la ville peut assumer une nouvelle condition d'existence à travers de la requalification des notions d'espace et de temps et de la compréhension du mouvement de reconstruction des collectivités locaux. Dans ce sens, on veut réfléchir sur un possible nouvel contenu géographique à travers de la connexion par ségrégation, notamment dans les villes.

ÍNDICE

Keywords: Pandemic, city, time, space, society.

Palavras-chave: Pandemia, cidade, tempo, espaço, sociedade.

Mots-clés: pandémie, ville, temps, espace, société.

Palabras claves: pandemia, ciudad, tiempo, espacio, sociedad.

\section{AUTOR}

\section{JORGE FRANÇA DA SILVA MEDEIROS}

Geógrafo. Doutor em Ciências (Geografia Humana, USP). Professor do Ensino Básico, Técnico e Tecnológico (COMAER/DIRENS/CTRB).E-MAIL: jorgefrancam@gmail.com 